\title{
Circulating interleukins (IL6)-An early predictor of insulin resistance
}

\author{
Naveen Bhartia Porwal', Archna Ghildiyal' ${ }^{2}$, Shraddha Singh ${ }^{3}$, Sandeep Bhattarcharya ${ }^{3}$, \\ Bushra Iqbal $^{4}$, Sunita Tiwari ${ }^{3}$, Kalpana Singh ${ }^{5}$
}

${ }^{1}$ Assistant Professor, Department of Physiology, Hind Institute of Medical Sciences, Sitapur, ${ }^{2}$ Associate Professor, ${ }^{3}$ Professor, ${ }^{4}$ Ph.D., Department of Physiology, ${ }^{5}$ Assistant Professor, Department of Biochemistry, King George's

Medical University, Lucknow, Uttar Pradesh, India

Background: Obesity is an increasing health concern that is highly correlated with the risk of developing insulin resistance and type- 2 diabetes. The insulin resistance represents an important association between obesity and the morbidities that lead concomitantly to increase sagittal abdominal diameter. The more resistant to insulin the individual is, the higher the risk for the development of type-2 diabetes and cardiovascular disease. Aims and Objective: The purpose of this study was to assess the correlation between insulin resistance and the production of cytokines (IL6) and to establish the relations between interleukins IL-6 and various anthropometric measurements. Material and Methods: A cross-sectional study was carried on 100 healthy individuals (55 males and 45 females) aged between 1825 years were enrolled after obtaining their written consent in Department of Physiology, KGMU. All the subjects were evaluated anthropometric: Body mass index (BMI), Waist circumference (WC), Hip circumference $(\mathrm{HC})$, Waist-hip ratio and Waist-height ratio as per standard protocol. Metabolic measures (Fasting glucose and insulin) were carried out using commercial kit (IRMA kit Immunotech- IM3210). Insulin resistance was measured using homeostasis model. Results: There was a significant positive correlation between interleukin 6 and fasting serum insulin $(r=0.56, p=0.001)$ \& HOMA IR $(r=0.57, p=0.001)$. Correlation between anthropometric measure and Interleukins (IL-6) was also observed to be positive and mild. Conclusion: A significant positive correlation was seen between IL- 6 and fasting serum insulin and HOMA-IR indicating IL 6 as a good predictive marker for insulin resistance.

Access this article online

Website:

http://nepjol.info/index.php/AJMS DOI: 10.3126/ajms.v7i6.15250

E-ISSN: 2091-0576

P-ISSN: 2467-9100

Key words: Insulin resistance, IL6, HOMA anthropometric measures

\section{INTRODUCTION}

Obesity is an expanding health concern that is profoundly correlated with the risk of developing insulin resistance and type- 2 diabetes. Substantial evidence indicates that a decreased inflammatory level accompanies obesity. This is evidenced by increased levels of inflammatory markers and cytokines in these individuals. C-Reactive Protein (CRP), plasminogen activator inhibitor-1, and fibrinogen are three such plasma markers. ${ }^{1}$ CRP production is affected in the liver at any rate to some extent by IL- 6 and may predict the development of type- 2 diabetes. ${ }^{1}$ Cytokines production by adipose tissue contributes to the inflammatory state of obesity. Adipose tissue-derived hormones and cytokines (adipokines) may likewise mediate insulin resistance in insulin target tissues.

It has been as of late demonstrated that monocytes infiltrate adipose tissue in proportion to adiposity and can be a source of adipose tissue-derived inflammatory cytokines, particularly TNF $\alpha .{ }^{2} \mathrm{TNF} \alpha$, in turn, may induce the release of additional adipokines by adipocytes. ${ }^{3}$ In support of the link among obesity, inflammation, and insulin resistance, IL- 6 and TNF $\alpha$, both known to be released from adipose tissue, have been shown to specifically bring aboutinsulin resistance in model systems. ${ }^{3}$ Nonetheless, a clear cause and effect relationship between inflammatory cytokines and insulin resistance 
and the development of type- 2 diabetes has not yet been completely resolved.

IL-6 is produced by adipocytes, monocytes, endothelial cells, and hepatocytes. In humans, roughly $15-35 \%$ of circulating IL-6 can be represented for by adipose tissue secretion. ${ }^{4}$ Moreover, circulating IL-6 is unequivocally connected with obesity and is a predictor of the development of type- 2 diabetes. ${ }^{5} \mathrm{IL}-6$ is an integral mediator of the acute phase response in the liver ${ }^{6}$ and controls the expression of CRP and fibrinogen. Subsequently, the connection between the expression of these acute phase proteins and type- 2 diabetes probably follows the dependence of expression on IL-6. One group has shown that IL-6 is an inhibitor of insulin signaling and insulin action in isolated hepatocytes, hepatoma cell lines, and livers of experimental mice. ${ }^{7}$

Importantly, IL-6 leads to insulin resistance in vivo when chronically administered to mice at levels similar to those found in obese individuals. ${ }^{7}$ IL-6 may exert its insulin action in other insulin target tissues as well. Recent studies have reported IL-6 inhibition of insulin action in muscle ${ }^{8}$ and 3T3L-1 adipocytes. ${ }^{3}$ Circulating IL-6 levels are elevated in insulin resistant states such as obesity, ${ }^{4}$ impaired glucose tolerance and type 2 diabetes. ${ }^{9}, 10$

There is a paucity of work which shows the direct relationship of IL6 to Insulin resistance. Therefore this study was planned to assess the correlation between insulin resistance and the production of cytokines (IL6) and to establish the relations between interleukins IL- 6 and various anthropometric measurements.

\section{MATERIAL AND METHODS}

The cross sectional study was conducted at Department of Physiology, King George's Medical University (KGMU), Lucknow after ethical approval by the institutes ethics committee. One hundred healthy individuals (55 males and 45 females) aged 18-25 years were enrolled after obtaining their written consent. A detailed medical history and examination of all volunteers were taken to ensure that they did not suffer from any medical illness - acute or chronic - at the time of study. The sample size was statistically calculated with $80 \%$ of power. Subjects having history of diabetes mellitus, endocrine disorder, metabolic disorder, and use of medication that affect carbohydrate and lipid metabolism were excluded from the study. Two $\mathrm{ml}$ venous fasting blood sample ( $>8$ hours) was collected from each subject and out of which $1 \mathrm{ml}$ blood was collected in fluoride vial, and remaining $1 \mathrm{ml}$ blood in plain vial. Serum and plasma were separated immediately, aliquot prepared and stored at $-80^{\circ} \mathrm{C}$ till further analysis.

\section{Anthropometrical measurements}

For measuring weight, the subject asked to stand still on the platform and weight measured with the help of a digital weighing machine. Height was measured using stadiometer with the help of a fixed scale. Body mass index was calculated by the formula; weight $(\mathrm{kg}) /$ height $\left(\mathrm{m}^{2}\right)$. Waist circumference (WC) was measured mid-way between iliac crest and lowermost margin of the ribs, in quiet breathing. Hip circumference (HC) was measured at the maximum protruding part of buttocks at the level of the greater trochanter with the subjects wearing minimal clothing. Waist hip ratio and Waist height ratio was calculated with the help of the formula WC (cm.)/HC (cm.) and WC $(\mathrm{cm}$.$) / height (\mathrm{cm}$.$) respectively.$

\section{Metabolic analysis}

Plasma was separated and frozen at $-80^{\circ} \mathrm{C}$ until the time of the assay. On the same day of sample collection, fasting plasma glucose was estimated using the glucose oxidase-peroxidase method (Microlab 300, Merck) usingsemi automated glucose analyzer Plasma insulin was estimated using a radio immunoassay kit (IRMA kit Immunotech- IM3210) with the help of a gamma counter. Insulin resistance was quantified using homeostasis model assessment (HOMA), an index of insulin resistance (IR) [HOMA-IR $=$ fasting insulin $(\mu \mathrm{U} / \mathrm{mL}) \times$ fasting plasma glucose $(\mathrm{mmol} / \mathrm{L}) / 22.5]^{11}$

\section{IL-6 protein measurements}

The IL-6 protein levels were measured in plasma samples using a specific human enzyme linked immunosorbent assay (ELISA) method. A capture Antibody highly specific for IL- 6 has been coated to the wells of the microtitre strip plate provided during manufacture. Binding of IL- 6 samples and known standards to the capture antibodies and subsequent binding of the biotinylated anti-IL-6 secondary antibody to the analyte is completed during the same incubation period. Any excess unbound analyte and secondary antibody is removed. The HRP conjugate solution is then added to every well including the zero wells, following incubation excess conjugate is removed by careful washing. A chromogen substrate is added to the wells resulting in the progressive development of a blue colored complex with the conjugate. The color development is then stopped by the addition of acid turning the resultant final product yellow. The intensity of the produced colored complex is directly proportional to the concentration of IL-6 present in the samples and standards. The absorbance of the color complex is then measured and the generated OD values for each standard are plotted against expected concentration forming a standard curve. This standard curve can then be used to accurately determine the concentration of IL-6 in a sample tested. 


\section{Statistical analysis}

The results are presented in mean \pm SD and percentages. The means compared by using unpaired t-test and one way analysis of variance (ANOVA). The Pearson Correlation Coefficient was calculated to find the direction of association between two continuous parameters. The linear regression analysis was applied to find the strength of the associations. The p-value $<0.05$ was considered significant. All the analysis was carried out by using SPSS 16.0 version (Chicago, Inc., USA).

\section{RESULTS}

Around more than half $(62 \%)$ of the subjects were aged between 20-22 years. The mean age of the subjects was 21.33 years with range between 18 to 24 years (Table 1 ). Subject's average height was $163.08( \pm 7.21) \mathrm{cm}$ with weight $60.53( \pm 8.74) \mathrm{kg}$. The Body mass index $(\mathrm{kg} / \mathrm{m} 2)$ was 22.71 $( \pm 2.72)$. The mean of Hip circumference $(\mathrm{cm})$ and Waist circumference $(\mathrm{cm})$ were $91.25( \pm 6.87)$ and $81.93( \pm 7.87)$ respectively. The mean of Waist-hip ratio and Waist-Height ratio were $0.89( \pm 0.09)$ and $0.50( \pm 0.05)$ respectively. Similarly, the mean of Fasting blood sugar (mg/dl), Fasting serum insulin $(\mu \mathrm{U} / \mathrm{ml})$ and HOMA-IR were 88.39 ( \pm 9.23$)$, $9.83( \pm 6.53)$ and $2.18( \pm 1.39)$ whereas interleukin-6 level was $14.35( \pm 8.78) \mathrm{pg} / \mathrm{ml}$. All the anthropometric parameters including BMI, HC WC WHR was mildly correlated with interleukin-6 level (Table 2). It was also seen that there was a significant positive correlation between interleukin 6 and fasting serum insulin $(\mathrm{r}=0.56, \mathrm{p}=0.001)$ \& HOMA IR $(\mathrm{r}=0.57, \mathrm{p}=0.001)$ (Table 3, Figures 1 and 2).

\section{DISCUSSION}

Type 2 diabetes mellitus, disease of the innate immune system, responsible for progressing cytokine-mediated acute phase response and low-grade chronic inflammation, which might be included in the atherosclerosis of diabetes mellitus. ${ }^{12}$ Along these lines it appears to be imperative to figure out if indications of an activated innate immune system are available before the onset of type 2 diabetes mellitus. Human adipose tissue has the tendency to produce and secrete a variety of proteins including cytokines (e.g. TNF ${ }^{13}$ and IL- $6^{14}$ ) and chemokines (e.g. IL- $8^{15}$ and monocyte chemo attractant and activating protein-1 (MCP-1) ${ }^{16}$ some of which may be involved in the development of obesity-related diseases through autocrine, paracrine or endocrine signaling., ${ }^{4,17}$ Studies on animal showed that the lack of proteins leads slow IL-6 response. ${ }^{18}$ Lower level of IL-6 levels in low-fat children compared to the obese are reported, so it is suggested that the proinflammatory markers must be considered in the classification of obesity. ${ }^{19,20}$

\begin{tabular}{lc} 
Table 1: Baseline demographics and clinical \\
features of the study population $(\mathbf{n = 1 0 0 )}$ \\
\hline Variable & Values \\
\hline Demographic profile & 17 \\
$<20$ & 62 \\
$20-22$ & 21 \\
$>22$ & $21.33 \pm 1.44(18-24)$ \\
Mean $\pm S D$ (Min.-Max.) & $163.08 \pm 7.21$ \\
Anthropometric measurements & $60.53 \pm 8.74$ \\
Height in cm & $22.71 \pm 2.72$ \\
Weight in kg & $91.52 \pm 6.87$ \\
Body mass index kg/m ${ }^{2}$ & $81.93 \pm 7.87$ \\
Hip circumference in cms & $0.89 \pm 0.09$ \\
Waist circumference in cms & $0.50 \pm 0.05$ \\
Waist-hip ratio & \\
Waist-height ratio & $88.39 \pm 9.23$ \\
Metabolic parameters & $9.83 \pm 6.53$ \\
Fasting blood sugar in mg/dl & $2.18 \pm 1.39$ \\
*Fasting serum insulin $(\mu U / \mathrm{ml})$ & $14.35 \pm 8.78$ \\
*HOMA- IR & \\
Interleukin-6 pg/ml & \\
* Since normal fasting serum insulin level is < $25 \mu \mathrm{U} / \mathrm{ml}$. The results shows within \\
normal range, so it may depends upon person to person
\end{tabular}

\begin{tabular}{lcc} 
Table 2: Correlation between anthropometric \\
parameters with interleukin-6 \\
\hline $\begin{array}{l}\text { Anthropometric } \\
\text { parameters }\end{array}$ & \multicolumn{2}{c}{ Interleukin-6 } \\
\cline { 2 - 3 } & Correlation & p-value \\
\hline BMI & 0.13 & 0.18 \\
HC & 0.26 & $0.007^{*}$ \\
WC & 0.33 & $0.001^{*}$ \\
WHR & 0.12 & 0.21 \\
Waist height ratio & 0.36 & $0.0001^{*}$ \\
\hline
\end{tabular}

\begin{tabular}{lcc} 
Table 3: Correlation between biochemical \\
parameters with interleukin-6 \\
\hline Biochemical parameters & \multicolumn{2}{c}{ Interleukin-6 } \\
\cline { 2 - 3 } & $\begin{array}{c}\text { Correlation } \\
\text { coefficient }\end{array}$ & p-value \\
\hline Fasting blood sugar & 0.11 & 0.24 \\
Fasting serum insulin & 0.56 & $0.001^{*}$ \\
HOMA IR & 0.57 & $0.001^{*}$ \\
\hline
\end{tabular}

However our previous study showed that BMI, waist circumference and WHR were positively correlated with insulin resistance. However, the waist circumference and waist height ratio were more strongly associated with insulin resistance compared to the other anthropometric parameter. ${ }^{21}$ Based upon our previous results this study was designed to find the correlation between anthropometric parameter, i.e. body mass index, hip circumference, waist circumference, waist hip ratio and waist height ratio to insulin resistance and Interleukins 6 level among the north Indian population.

Various anthropometric measures have shown the best correlation with visceral fat followed by waist circumference 


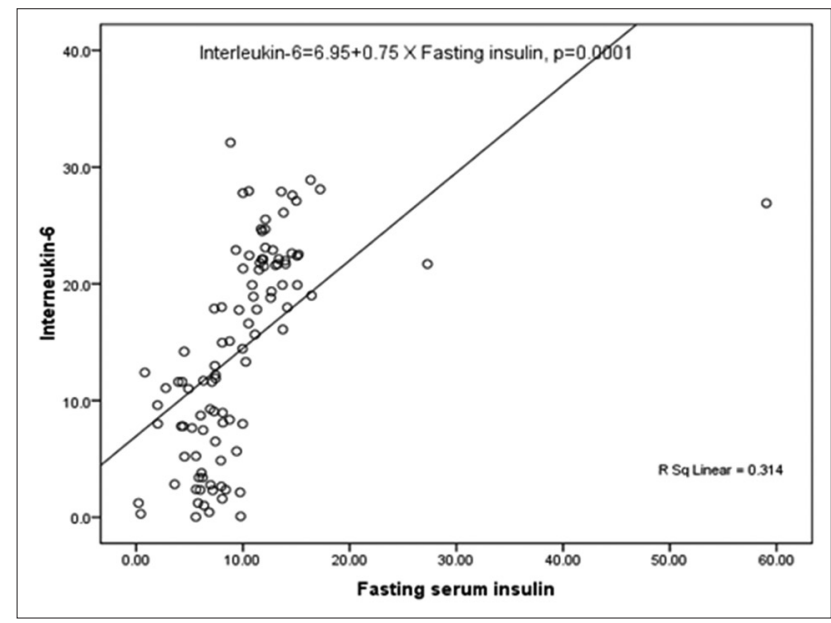

Figure 1: Scatter diagram showing correlation between interleukin-6 and fasting insulin

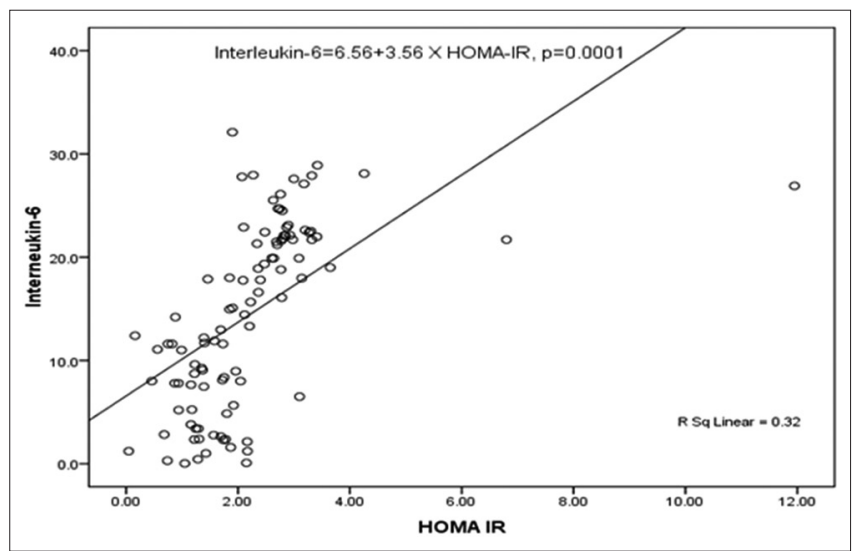

Figure 2: Scatter diagram showing correlation between interleukin-6 and HOMA-IR

and even among non diabetic person, increase in visceral fat is associated with insulin sensitivity. ${ }^{22}$ Our present study showed that prevalence of waist hip ratio was higher among male than female (Table 4) and difference was statistically significant $(p=001)$. This may be due to differential deposition of fat in male and female. $.^{23} \mathrm{IL}-6$ level in healthy subjects is decreased in both sexes. ${ }^{24}$ However our study reveals this fact and shows a significant high level of IL-6 in females as compared to males. Our study shows that anthropometric parameters including BMI, HC WC WHR was mildly correlated with IL-6 level (Table 2).

In our study there was a significant positive correlation was observed between IL- 6 and fasting serum insulin. IL-6 levels are also well correlated with HOMA-IR (Table 3). This is in close finding of study which found that SAD identifies insulin resistance and subclinical inflammation in Swedish population. ${ }^{25}$ We studied the correlation of insulin resistance and inflammatory condition with anthropometric parameters, which is evident by the increase level of IL6 in our subjects as

\begin{tabular}{|c|c|c|c|}
\hline \multirow{2}{*}{$\begin{array}{l}\text { Anthropometric } \\
\text { parameters }\end{array}$} & \multicolumn{2}{|c|}{ Mean $\pm S D$} & \multirow[t]{2}{*}{ p-value } \\
\hline & $\begin{array}{l}\text { Male } \\
(n=55)\end{array}$ & $\begin{array}{c}\text { Female } \\
(n=45)\end{array}$ & \\
\hline Body mass index $\mathrm{kg} / \mathrm{m}^{2}$ & $23.19 \pm 2.68$ & $22.12 \pm 2.68$ & 0.05 \\
\hline Hip circumference in cms & $88.20 \pm 6.07$ & $95.57 \pm 5.51$ & $0.001^{*}$ \\
\hline Waist circumference in $\mathrm{cms}$ & $83.78 \pm 7.97$ & $79.66 \pm 7.20$ & $0.009^{*}$ \\
\hline Waist-hip ratio & $0.94 \pm 0.07$ & $0.83 \pm 0.08$ & $0.001^{*}$ \\
\hline Waist-Height ratio & $0.50 \pm 0.04$ & $0.51 \pm 0.05$ & 0.70 \\
\hline
\end{tabular}

we know that IL-6 is a good marker for inflammatory conditions.

Our present study (Table 3, Figure 2) showed a strong correlation between IL-6 and HOMA-IR. Recently, this correlation between circulating IL- 6 and insulin sensitivity was confirmed using the "gold standard for insulin sensitivity"; the hyperinsulinemic-euglycaemic clap. ${ }^{26}$ Infusion of rhIL-6 to humans increased whole body glucose disposal and glucose oxidation, but increased hepatic glucose production. ${ }^{27}$

IL-6 can alter adipocyte metabolism via autocrine or paracrine mechanism and have a local influence on insulin sensitivity. ${ }^{26}$ Basal serum IL-6 levels are found to be higher in type-2 diabetic patients. ${ }^{28}$ In one study, both IL- 6 mRNA in adipose tissue and IL-6 serum levels were reduced with weight loss after three weeks of a very low calorie diet in obese women. ${ }^{29}$ The reduction in IL-6 levels could play a role in this improvement, since several studies found a significant correlation between circulating IL-6 levels and insulin sensitivity measured by either an intravenous glucose tolerance test. ${ }^{30}$ Several genetic study support the relationship between IL- 6 and insulin sensitivity.Since IL-6 gene polymorphism affects the relationship between insulin sensitivity, postload glucose levels, and peripheral white blood cell count. ${ }^{31} \mathrm{It}$ appeared that subjects with an IL-6 gene polymorphism had lower IL-6 levels, a lower area under the glucose curve after an oral glucose tolerance test, lower glycosylated haemoglobin (HbA1c) and fasting serum insulin levels and an increased insulin sensitivity index as compared with carriers of the normal IL-6 allele, despite similar age and BMI. ${ }^{32}$

Our studies are of interest since Inter-leukins likes IL6 have been suggested to be involved in the pathogenesis of many diseases that are linked with excess amounts of adipose tissue e.g. atherosclerosis and cardiovascular disease. ${ }^{32,33}$ In addition, elevated circulating levels of IL- 8 have been reported in patients with type 1 and type 2 diabetes ${ }^{34}$ linking these Interleukins with insulin resistance. 


\section{CONCLUSION}

Our study concludes that anthropometric parameters including BMI, HC WC WHR was mildly correlated with interleukin-6 level. However a significant positive correlation was seen between IL-6 and HOMA-IR indicating, IL 6 as a good predictive marker for insulin resistance. Further studies are needed in a larger population to clarify these relations as a good predictive value in Type II Diabetics.

\section{REFERENCES}

1. Pradhan AD, Manson JE, Rifai N, Buring JE, and Ridker PM. C-reactive protein, interleukin 6 , and risk of developing type 2 diabetes mellitus. J Am Med Assoc 2001; 286:327-334.

2. Weisberg SP, McCann D, Desai M, Rosenbaum M, Leibel RL and Ferrante AW. Obesity is associated with macrophage accumulation in adipose tissue. J Clin Invest 2003; 112:1796-1808.

3. Rotter V, Nagaev I and Smith U. Interleukin-6 (IL-6) induces insulin resistance in 3T3-L1 adipocytes and is, like IL-8 and tumor necrosis factor- $\alpha$, over expressed in human fat cells from insulin-resistant subjects. J Biol Chem 2003; 278:45777-45784.

4. Mohamed-Ali V, Goodrick S, Rawesh A, Katz DR, Miles JM, Yudkin JS, et al. Subcutaneous adipose tissue releases interleukin-6, but not tumor necrosis factor- $\alpha$, in vivo. J Clin Endocrinol Metab 1997; 82:4196-4200.

5. Kern PA, Ranganathan S, Li C, Wood L and Ranganathan G. Adipose tissue tumor necrosis factor and interleukin-6 expression in human obesity and insulin resistance. Am J Physiol 2001; 280:E745-E751.

6. Baumann $\mathrm{H}$ and Gauldie J. The acute phase response. Immunol Today 1994; 15:74-80.

7. Klover PJ, Zimmers TA, Koniaris LG and Mooney RA. Chronic exposure to interleukin- 6 causes hepatic insulin resistance in mice. Diabetes 2003; 52:2784-2789.

8. Kim HJ, Higashimori T, Park SY, Choi H, Dong J, Kim YJ, et al. Differential effects of interleukin- 6 and -10 on skeletal muscle and liver insulin action in vivo. Diabetes 2004; 53:1060-1067.

9. Tonjes A, Fasshauer M, Kratzsch J, Stumvoll M and Blüher M. Adipokine Pattern in Subjects with Impaired Fasting Glucose and Impaired Glucose Tolerance in Comparison to Normal Glucose Tolerance and Diabetes. PLoS ONE 2010; 5 (11). http:// dx.doi.org/10.1371/journal.pone.0013911.

10. Muller S, Martin S, Koenig W, Hanifi-Moghaddam P, Rathmann W, Haastert B, et al. Impaired glucose tolerance is associated with increased serum concentrations of interleukin 6 and co-regulated acute-phase proteins but not TNF-alpha or its receptors. Diabetologia 2002; 45: 805-812.

11. World Health Organization. (2000) The Asia-Pacific Perspective: Redefining Obesity and its Treatment. World Health Organization, Geneva.

12. Fernandez-Real JM and Ricart W. Insulin resistance and chronic cardiovascular inflammatory syndrome. Endrocrine Rev 2002; 24: 278-301.

13. Dandona P, Weinstock R, Thusu K, Abdel-Rahman E, Aljada A and Wadden T. Tumor necrosis factor-alpha in sera of obese patients: fall with weight loss. Journal of Clinical Endocrinology and Metabolism 1998; 83: 2907-2910.

14. Bastard JP, Jardel C, Bruckert E, Blondy P, Capeau J, Laville M, et al. Elevated levels of interleukin 6 are reduced in serum and subcutaneous adipose tissue of obese women after weight loss. Journal of Clinical Endocrinology and Metabolism 2000; 85: 3338-3342.

15. Bruun JM, Pedersen SB and Richelsen B. Regulation of interleukin 8 production and gene expression in human adipose tissue in vitro. Journal of Clinical Endocrinology and Metabolism 2001; 86: 1267-1273.

16. Gerhardt CC, Romero IA, Cancello R, Camoin $L$ and Strosberg AD. Chemokines control fat accumulation and leptin secretion by cultured human adipocytes. Molecular and Cellular Endocrinology 2001; 175: 81-92.

17. Steppan CM and Lazar MA. Resistin and obesity-associated insulin resistance. Trends in Endocrinology and Metabolism 2002; 13:18-23.

18. Cruickshank AM, Jennings $G$, Fearon $K H$, Elia $M$ and Shenkin $A$. Serum interleukin 6 (IL-6) - effect of surgery and under nutrition. Clin Nutr 1991; 10(Suppl):65-69.

19. Songür N, Kuru B, Kalkan F, Ozdilekcan C, Cakmak H and Hizel N. Serum interleukin-6 levels correlate with malnutrition and survival in patients with advanced non-small cell lung cancer. Tumori 2004; 90(2):196-200.

20. Clark MK and Dillon JS. BMI misclassification, leptin, C-reactive protein, and interleukin- 6 in young women with differing levels of lean and fat mass. Obes Res Clin Pract 2011; 5(2):e85-e92.

21. Porwal NB, Singh S, Verma N, Bhattacharya S, Singh K, Madesiya $A$, et al. New surrogate anthropometrical markers for early detection of insulin resistance. International Journal of Biomedical Research 2015; 6(04): 246-250.

22. Deepa M, Pradeepa R, Rema M, Mohan A, Deepa R, Shanthirani $S$, et al. The Chennai Urban Rural Epidemiology Study (CURES) - Study Design And Methodology (Urban Component) (CURES - 1).

23. Geer EB and Shen W. Gender differences in insulin resistance, body composition, and energy balance. Gend. Med 2009; 6 Suppl 1: 60-75.

24. Martos-Moreno GA, Barrios $\vee$ and Argente J. Normative data for adiponectin, resistin, interleukin 6 , and leptin/receptor ratio in a healthy Spanish pediatric population: relationship with sex steroids. Eur J Endocrinol 2006; 155(3):429-434.

25. Petersson H, Daryani A and Riserus U. Sagittal Abdominal Diameter as a marker of inflammation and insulin resistance among immigrant women from the Middle-East and native Swedish women: a cross-section study. Cardiovasc-Diabetol 2007; 10: 1186/1475-2840-6-10.

26. Bastard JP, Maachi M, Nhieu JT van, Jardel C, Bruckert E, Grimaldi A, et al. Adipose tissue IL-6 content correlates with resistance to insulin activation of glucose uptake both in vivo and in vitro. J Clin Endocrinol Metab 2002; 87(5):2084-2089.

27. Stouthard JM, Romijn JA, Pol T van der, Endert E, Klein S, Bakker PJ, et al. Endocrinologic and metabolic effects of interleukin-6 in humans. Am J Physiol 1995:813-819.

28. Pickup JC, Chusney GD, Thomas SM and Burt D. Plasma interleukin-6, tumour necrosis factor alpha and blood cytokine production in type 2 diabetes. Life Sci 2000; 67(3):291-300.

29. Bastard JP, Jardel C, Bruckert E, Blondy P, Capeau J, Laville M, et al. Elevated levels of interleukin 6 are reduced in serum and subcutaneous adipose tissue of obese women after weight loss. J Clin Endocrinol Metab 2000; 85(9):3338-3342.

30. Kern PA, Ranganathan S, Li C, Wood L and Ranganathan G. Adipose tissue tumor necrosis factor and interleukin-6 expression in human obesity and insulin resistance. Am J Physiol 2001; 280:E745-E751.

31. Fernandez-Real JM, Broch $M$, Vendrell J, Gutierrez C, Casamitjana R, Pugeat M, et al. Interleukin-6 gene polymorphism and insulin sensitivity. Diabetes 2000; 49(3):517-520. 
32. Reape TJ and Groot PH. Chemokines and atherosclerosis. Atherosclerosis 1999; 147: 213-225.

33. Shin WS, Szuba A and Rockson SG. The role of chemokines in human cardiovascular pathology: enhanced biological insights.
Atherosclerosis 2002; 160: 91-102.

34. Zozulinska D, Majchrzak A, Sobieska M, Wiktorowicz K and Wierusz-Wysocka B. Serum interleukin-8 level is increased in diabetic patients [letter]. Diabetologia 1999; 42: 117-118.

Authors Contribution:

NBP, AG, SS - Contributes in concept designing of the study, reviewed the literature, manuscript preparation and critical revision of the manuscript;

KS, BI - Contributes in conceptualized study, literature search, statistically analysis and interpreted, prepared first draft of manuscript; SB, ST - Assisted in

statistical analysis and data interpretation.

Source of Support: Nil. Conflict of Interest: None. 